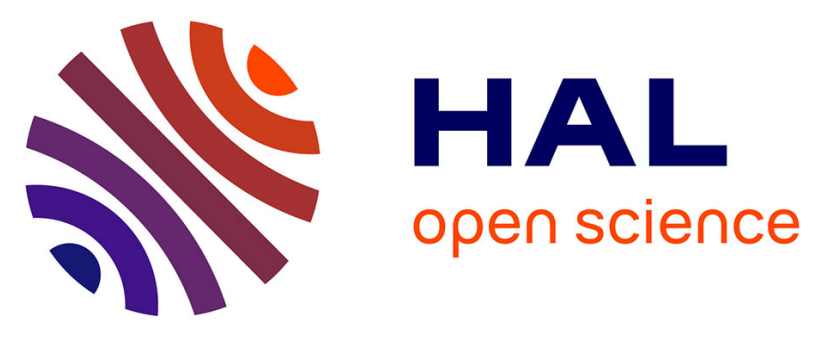

\title{
Electron beam radiation effects on properties and ecotoxicity of PHBV/PLA blends in presence of organo-modified montmorillonite
}

Idris Zembouai, Mustapha Kaci, Stéphane Bruzaud, Isabelle Pillin, Jean-Luc Audic, Shima Shayanfar, Suresh D Pillai

\section{To cite this version:}

Idris Zembouai, Mustapha Kaci, Stéphane Bruzaud, Isabelle Pillin, Jean-Luc Audic, et al.. Electron beam radiation effects on properties and ecotoxicity of PHBV/PLA blends in presence of organo-modified montmorillonite. Polymer Degradation and Stability, 2016, 132, pp.117-126. 10.1016/j.polymdegradstab.2016.03.019 . hal-01295517

HAL Id: hal-01295517

https://hal-univ-rennes1.archives-ouvertes.fr/hal-01295517

Submitted on 20 Jun 2016

HAL is a multi-disciplinary open access archive for the deposit and dissemination of scientific research documents, whether they are published or not. The documents may come from teaching and research institutions in France or abroad, or from public or private research centers.
L'archive ouverte pluridisciplinaire HAL, est destinée au dépôt et à la diffusion de documents scientifiques de niveau recherche, publiés ou non, émanant des établissements d'enseignement et de recherche français ou étrangers, des laboratoires publics ou privés. 


\title{
Electron Beam Radiation Effects on Properties and Ecotoxicity of PHBV/PLA
} Blends in Presence of Organo-Modified Montmorillonite

Idris Zembouai ${ }^{\mathrm{a}, \mathrm{c}}$, Mustapha Kaci ${ }^{\mathrm{a}}$, Stéphane Bruzaud ${ }^{\mathrm{b} *}$, Isabelle Pillin ${ }^{\mathrm{b}}$, Jean-Luc Audic ${ }^{\mathrm{d}}$, Shima Shayanfare, Suresh D. Pillai ${ }^{\mathrm{e}}$

âLaboratoire des Matériaux Polymères Avancés (LMPA), Université de Bejaia 06000, Algeria

bLaboratoire d’Ingénierie des Matériaux de Bretagne (LIMATB), Université de Bretagne-Sud, Rue de Saint Maudé, 56321 Lorient Cedex, France

${ }^{\mathrm{c}}$ Faculté de Technologie, Université Saad Dahlab-Blida1, Blida 09000, Algeria

${ }^{\mathrm{d}}$ Ecole Nationale Supérieure de Chimie de Rennes, CNRS, UMR 6226, 11 Allée de Beaulieu, CS 50837, 35708 Rennes Cedex 7, France

${ }^{\mathrm{e}}$ National Center for Electron Beam Research, Texas A\&M University, Texas, USA

*Corresponding author: E-mail: stephane.bruzaud@univ-ubs.fr Tel.: +332 978745 84; fax: +33297874588

\begin{abstract}
The present article reports a study of oxidative degradation under eBeam irradiation of neat PHBV, neat PLA and PHBV/PLA blend (50/50 w/w) with and without Cloisite 30B (C30B) (3 wt\%) at absorbed doses of 1 and $10 \mathrm{kGy}$. The changes in the chemical structure, the molecular weight, the thermal, mechanical and barrier properties as well as the morphology were evaluated. The data showed that eBeam irradiation of PHBV/PLA blend leads to oxidation reactions involving ester groups in both neat PLA and neat PHBV resulting in the formation of hydroperoxides groups. The presence of C30B in the polymer blend has no influence on the nature of the degradation process. However, the good dispersion of C30B nanoparticles provides more stability to the molar mass and the thermal, mechanical and barrier properties of PHBV/PLA blend. At absorbed dose of $10 \mathrm{kGy}$, the irradiated samples are completely safe. Furthermore, ecotoxicity testing of both non irradiated and irradiated samples clearly showed no toxicity.
\end{abstract}

Keywords: PHBV, PLA, Cloisite 30B, polymer blend, eBeam irradiation and degradation.

\section{Introduction}


Food packaging manufacturers have become increasingly aware of customer demands relating to concerns about food quality, safety, and most importantly of environmental sustainability. Aseptic food packaging material is therefore essential to preserve food quality over time [1]. For biodegradable packaging, these materials have to be sterilized or decontaminated prior to use to protect against possible microbial contamination [2]. Since our knowledge about polyhydroxyalcanoates (PHA) for food packaging is rather limited, the challenge is to produce biodegradable primary packaging materials which remain stable without affecting mechanical and barrier properties as well as not resulting in toxicological side-effects during both storage and usage [3]. Several methods for decontamination are well documented in literature and these include mainly, hydrogen peroxide $\left(\mathrm{H}_{2} \mathrm{O}_{2}\right)$ technology, wet steam, UVlight and ionizing radiation [4]. Ionizing radiation is an effective technology for sterilization as well as for other applications such as food pasteurization and environmental remediation [5]. Recent advances in electron-beam technology (eBeam) have made this mode of sterilization a worthy competitor to the traditional gamma processing [6]. There are fundamental differences between eBeam irradiation technology and y-irradiation in terms of the generation of the ionizing radiation, the penetration of eBeam as compared to $\mathrm{\gamma}$ irradiation. eBeam technology is now growing in importance given the availability of compact, energy efficient, high energy (10 MeV) eBeam generating linear accelerator [7]. The typical dose rates of $\mathrm{\gamma}$-irradiation are approximately between 5 and $20 \mathrm{kGy} / \mathrm{h}$, while the dose rate of eBeam irradiation is around 3-5 kGy/s. Due to this huge dose rate difference, irradiation exposure time is also significantly affected since eBeam processing would take only a few seconds for the same dose delivery compared to several hours for $\mathrm{\gamma}$-irradiation. The effect of ionizing radiation on polymer materials was a subject of many investigations [810]. The main conclusion from these studies was that the changes affecting the molecular structure of irradiated polymers such as the molecular weight increase (crosslinking) or the molecular weight decrease (chain scission) depends on several parameters involving the structure of the polymer, the dose rate, the conditions of irradiation besides the formation of volatile radiolytic products [7]. However, little is known about the durability of polymer blends, especially those based on biopolymers like PHBV/PLA and the effects of such environment on the structure-property relationships under ionizing radiations. Previous studies on PHBV/PLA blends [10-14] were performed in the context of structure/properties relationships, compatibility, recycling, and durability under $\gamma$-irradiation. In the present work, the objective was to investigate how the radiation stability of PHBV/PLA blends in presence of C30B is affected by eBeam irradiation at absorbed doses of 1 and $10 \mathrm{kGy}$. The changes 
induced in terms of chemical structure, morphology, molar mass, thermal, mechanical and barrier properties as well as ecotoxicity were evaluated by several techniques for each absorbed dose.

\section{Experimental part}

\subsection{Materials used}

PLA was supplied in pellets form by NatureWorks under the trade name 7001D. The polymer is a semi crystalline one having the following properties: density $=1.25 \mathrm{~g} / \mathrm{cm}^{3}$, MFI $=6 \mathrm{~g} / 10$ $\min \left(210^{\circ} \mathrm{C}, 2.16 \mathrm{~kg}\right), \mathrm{T}_{\mathrm{g}}=60^{\circ} \mathrm{C}$ and $\mathrm{T}_{\mathrm{m}}=160^{\circ} \mathrm{C}$.

PHBV was manufactured by Tianan Biological Materials Co. Ltd. (China) and commercialized in pellets form under the trade name ENMAT Y1000P. According to the manufacturer, PHBV has the following properties: density $=1.25 \mathrm{~g} / \mathrm{cm}^{3}, \mathrm{~T}_{\mathrm{g}}=8^{\circ} \mathrm{C}$ and $\mathrm{T}_{\mathrm{m}}=165^{\circ} \mathrm{C}$. This grade has been comprehensively characterized in a recent paper [11].

Cloisite 30B (C30B) is an organically modified montmorillonite, which is commercially available and supplied by Southern Clay Products (Texas). C30B is a montmorillonite modified with bis-(2-hydroxyethyl)methyl tallow alkyl ammonium cations. C30B was dried under vacuum at $60^{\circ} \mathrm{C}$ for at least $24 \mathrm{~h}$ before processing.

\subsection{Sample preparation}

Prior to use, all materials were dried under vacuum at $60^{\circ} \mathrm{C}$ for $24 \mathrm{~h}$. Drying was necessary to minimize the hydrolytic degradation of the polymers during melt processing. Samples of various blend compositions (shown in Table 1) were prepared in an internal (model W50 EHT) mixer according to a previously described procedure [11]. The mixing temperature, screw speed and residence time were set at $180^{\circ} \mathrm{C}, 50 \mathrm{rpm}$ and $8 \mathrm{~min}$, respectively. The extruded materials were ground into pellets. Prior to compression molding, the pellets were dried over $12 \mathrm{~h}$ under vacuum at $60^{\circ} \mathrm{C}$ and compression molded in a Carver ${ }^{\circledR}$ hydraulic press at $180^{\circ} \mathrm{C}$ under a pressure of 40 bars for 3 min to obtain thin films of about $150 \mu \mathrm{m}$ of thickness.

\section{Table 1}

\subsection{Electron beam irradiation}

The eBeam irradiation of the plastic films was performed at the National Center for Electron Beam Research at Texas A\&M University using a vertically mounted $10 \mathrm{MeV}, 18 \mathrm{~kW}$ commercial scale linear accelerator at room temperature $\left(25^{\circ} \mathrm{C}\right)$. Alanine films (Kodak) were 
placed below the film samples to measure the actual absorbed eBeam dose. After irradiation, the alanine dosimeters were analyzed to measure the absorbed dose using a Bruker E-scan spectrometer (Bruker, Billerica, MA). Two target doses of 1 and $10 \mathrm{kGy}$ were delivered and the measured doses were reported as $1.04 \pm 0.01 \mathrm{kGy}$ and $9.89 \pm 0.13 \mathrm{kGy}$, respectively. The dose rate was approximately $3000 \mathrm{~Gy} / \mathrm{s}$. A group of non irradiated sample (0 kGy) was considered as control samples.

\subsection{Technical characterization}

\subsubsection{Fourier Transform Infrared Spectroscopy (FT-IR)}

FT-IR spectra of various film samples were recorded by an FT-IR spectrometer (Shimadzu $8400 \mathrm{M}$ ) using $4 \mathrm{~cm}^{-1}$ resolution and 40 scans. All spectra were recorded in attenuated total reflectance (ATR) mode in the $4000-400 \mathrm{~cm}^{-1}$ region, with an IR beam always penetrating with the same depth $(4 \mu \mathrm{m})$.

\subsubsection{Molar mass change determined by size exclusion chromatography (SEC)}

SEC was used to determine both the weight and number-average molecular weights of PHBV/PLA blends before and after eBeam irradiation. The apparatus was equipped with a set of three columns: two ResiPore and one PL gelMixed C (Polymer Labs.). The detection system was composed by a refractometer and a UV detector. Chloroform was used as an eluant with a flow rate of $0.8 \mathrm{~mL} / \mathrm{min}$. The elution profiles were analyzed using the Empower SEC module software (Waters). Calculations were based on calibration curves obtained from polystyrene standards ranging from 580 up to $1 \times 10^{6} \mathrm{~g} / \mathrm{mol}$. The weight-average molecular weight $\bar{M}_{w}$ and number-average molecular weight $\bar{M}_{n}$ were obtained from the SEC analysis.

The average number of random chain scissions per unit mass $\left(\mathrm{n}_{\mathrm{t}}\right)$ was calculated according to the following Eq. (1) [15]:

$n_{t}=\frac{1}{\overline{M n_{t}}}-\frac{1}{\overline{M n_{0}}}$

Where, $\mathrm{Mn}_{\mathrm{t}}$ and $\mathrm{Mn}_{0}$ are the number-average molecular weight at a given dose and nonirradiated samples, respectively.

\subsubsection{Differential Scanning Calorimetry (DSC)}

DSC analysis was performed on weighted samples of about10 mg, using Mettler-Toledo DSC-882 equipment. The samples were first heated from -40 to $200^{\circ} \mathrm{C}$ at a heating rate of 
$10^{\circ} \mathrm{C} / \mathrm{min}$ under nitrogen atmosphere and maintained at this temperature for 2 min to eliminate thermal history. The samples were then cooled to $-40^{\circ} \mathrm{C}$ at a cooling rate of $10^{\circ} \mathrm{C} / \mathrm{min}$. Then the samples were reheated to $200^{\circ} \mathrm{C}$ at $10^{\circ} \mathrm{C} / \mathrm{min}$ so that the melting could be studied. From DSC thermograms, thermal characteristics, i.e. crystallization temperature $\left(\mathrm{T}_{\mathrm{c}}\right)$, cold crystallization temperature $\left(\mathrm{T}_{\mathrm{cc}}\right)$, crystallization enthalpy $\left(\Delta \mathrm{H}_{\mathrm{c}}\right)$, cold crystallization enthalpy $\left(\Delta \mathrm{H}_{\mathrm{cc}}\right)$, melting temperature $\left(\mathrm{T}_{\mathrm{m}}\right)$ and melting enthalpy $\left(\Delta \mathrm{H}_{\mathrm{m}}\right)$ were determined.

\subsubsection{Thermogravimetric analysis (TGA)}

TGA experiments were carried out in a thermal analyzer (Setaram TG/DTA 92-10) using a heating rate of $10^{\circ} \mathrm{C} / \mathrm{min}$ under nitrogen atmosphere, between 20 and $600^{\circ} \mathrm{C}$. The average sample mass was almost $10 \mathrm{mg}$.

\subsubsection{Nanoindentation test}

Nanoindentation measurements were made on the film sections after inclusion in an epoxy resin and polishing. We used a commercial nanoindentation system (Nanoindenter XP, MTS Nano Instruments) at room temperature $\left(23 \pm 1^{\circ} \mathrm{C}\right)$ with a continuous stiffness measurement (CSM) technique, equipped with a three-side pyramid (Berkovich) indenter. We worked with $3 \mathrm{~nm}$ amplitude, $45 \mathrm{~Hz}$ oscillations using a $0.05 \mathrm{~s}^{-1}$ loading rate. Measurements were taken at depths to $1000 \mathrm{~nm}$. For each sample, around 60 indents were performed. The detailed nanoindentation principle and the method used to determine hardness and elastic modulus were described in previous work [16].

\subsubsection{Scanning electron microscopy (SEM)}

Morphological changes were observed using a Jeol JSM-6031 scanning electron microscope to examine the fracture surface of the film samples before and after eBeam irradiation. The neck region for the broken specimens fractured in liquid nitrogen is parallel to the draw direction in order to reveal the internal morphology. Prior to observation, the fracture surface was coated with a thin gold layer by means of a polaron sputtering apparatus.

\subsubsection{Transmission electron microscopy (TEM)}

The morphological structure of the samples before and after eBeam irradiation was observed using a transmission electron microscope (TEM) of a Model JEM-1200EX, JEOL, Tokyo, Japan (cold field emission gun $100 \mathrm{kV}$, point to point resolution $=0.23 \mathrm{~nm}$ ). Prior to analysis, the samples were prepared using an ultramicrotome Leica UC7 equipped with a diamond 
knife. The ultrathin sections were cut at room temperature and under dry conditions and then transferred onto 300 mesh Cu grids coated with a lacy carbon film.

\subsubsection{Water vapor permeability test}

The water vapor permeation of the film was studied using the "Cups methods" referring to ISO 7783. The experimental setting consists of a cylindrical vessel filled with a desiccant powder and sealed with the investigated film. $10 \mathrm{~g}$ of $\mathrm{CaCl}_{2}$ were used as the desiccant powder, while temperature was set to $23^{\circ} \mathrm{C}$ with a relative humidity of $50 \%$. This method consists of monitoring the water mass uptake of the desiccant powder with time. The Water Vapor Transmission Rate (WVTR) is then calculated from the slope of the mass uptake profile versus time as soon as the steady state is reached using Eq.(2) [11]:

$$
W V P=\frac{W V T R \times e}{\Delta P}
$$

Where, WVP is the water vapor permeability coefficient $\left(\mathrm{g} \cdot \mathrm{m}^{-1} \cdot \mathrm{s}^{-1} \cdot \mathrm{Pa}^{-1}\right)$, WVTR is the water vapor transmission rate $\left(\mathrm{g} \cdot \mathrm{m}^{-2} \cdot \mathrm{s}^{-1}\right)$, e is the film thickness $(\mathrm{m})$ and $\Delta \mathrm{P}$ is the water vapor partial pressure difference $(\mathrm{Pa})$. From the experimental conditions, the water vapor $\Delta \mathrm{P}$ was $1.4 \times 10^{3}$ Pa calculated at $23^{\circ} \mathrm{C}$ and a relative humidity $(\mathrm{RH})$ of $50 \%$. Four film samples from each formulation were tested and the results were arithmetically averaged.

\subsubsection{Ecotoxicity Test}

After eBeam process, the various film samples were cut into $1 \mathrm{x} 1 \mathrm{~cm}$ pieces and were placed individually in different $5 \mathrm{~mL}$ glass vials containing $3 \mathrm{~mL}$ of three different food simulants to enhance probable polymer migration from film into the liquid. The selected food simulants were distilled water, olive oil and $10 \%(\mathrm{v} / \mathrm{v})$ ethanol solution. These simulants were selected according to US FDA and EU regulations (European Commission, 2002; FDA, 1999). The vials containing the films were placed in a shaking incubator at $35^{\circ} \mathrm{C}$ for 10 days. After this incubation period, the polymer pieces were removed from the glass vials and the liquids in the vials were tested for toxicity using Deltatox II Analyser (Modern Water Monitoring Ltd., Cambridge, UK). The results were recorded as a \% light gain or light loss (as compared to the background matrices). Toxicity thresholds were based on the background matrices used as the food simulants. Samples showing \% light loss greater than observed in the food simulants were reported as positive for toxicity. All the toxicity tests were conducted using three replications. 


\section{Results and discussion}

\subsection{Fourier transform-infrared (FT-IR) spectroscopy analysis}

FT-IR analysis was used to assess the changes induced by eBeam irradiation on the chemical structure of PHBV/PLA samples. In this respect, FT-IR spectra of neat PHBV, neat PLA, PHBV/PLA blend and PHBV/PLA/C30B nanocomposite before exposure and at target dose of $10 \mathrm{kGy}$ are shown in Figure 1, 2, 3 and 4, respectively. Analysis of the FT-IR spectra concerned two main regions, i.e. carbonyl (a) and hydroperoxides (b), where changes are expected. As reported in literature [17], neat PLA exhibits a large absorption band in the region 1850 - $1650 \mathrm{~cm}^{-1}$ corresponding to ester group (Figure 1(a)). At target dose of 10 kGy, the characteristic absorption band of the irradiated PLA becomes wider and its intensity slightly decreases compared to the non irradiated one. This could be explained as a result of oxidation reactions involving the ester groups of PLA leading to the formation of various oxidative species and hydroxyl groups contained in hydroperoxides [17]. In Figure 1(b), which is relative to the region $3600-3400 \mathrm{~cm}^{-1}$, the PLA spectrum exhibits three large absorption bands located at 3656, 3570 and $3565 \mathrm{~cm}^{-1}$, which are attributed to $\mathrm{OH}$ groups in alcohols, hydroperoxides and carboxylic acids. At target dose of $10 \mathrm{kGy}$, the absorption bands intensity becomes stronger confirming the occurrence of oxidation reactions during eBeam irradiation. The oxidation reactions lead to the formation of hydroperoxides derivatives which degrade in compounds containing carboxylic acids and diketone end groups.

Concerning the PHBV, the same comments can be made, as the slight decrease in intensity and the widening of the absorption band located between 1850 and $1650 \mathrm{~cm}^{-1}$ (Figure 2(a)). Moreover, the intensity evolution of the bands (centered at 3635, 3550 and $3439 \mathrm{~cm}^{-1}$ ) after eBeam irradiation of PHBV follows the same trend as that of PLA, suggesting that the degradation mechanisms are quite similar (Figure 2(b)).

Figure 3 shows the structural modifications of PHBV/PLA blends at absorbed doses of 1 and $10 \mathrm{kGy}$. In the case of the large band located between 1850 and $1650 \mathrm{~cm}^{-1}$ (Figure 3(a)), its intensity regularly decreases as a function of absorbed dose, while its widening becomes stronger. In the region of 1900-1500 $\mathrm{cm}^{-1}$ (Figure 3(b)), the characteristic absorption bands at 3652, 3505 and $3438 \mathrm{~cm}^{-1}$ regularly increases with increasing the absorbed dose. This means that eBeam irradiation of PHBV/PLA blend leads to oxidation reactions of ester groups in both PHBV and PLA inducing the formation of hydroxyl groups.

Finally, the incorporation of C30B in PHBV/PLA blend seems to have no influence on the nature of the degradation process. Figure 4(a) and (b) points out the same trend in the evolution of the different characteristic bands in the whole spectrum. Similar conclusions for 
the nature of degradation mechanism can be deduced in the presence or in the absence of C30B.

\subsection{Molar mass}

The values of $\bar{M}_{w}, \bar{M}_{n}$ and molecular weight distribution (MWD) determined by SEC analysis of the neat PHBV, neat PLA, PHBV/PLA blend and PHBV/PLA/C30B nanocomposite samples as a function of the irradiation dose are presented in Table 2 . It is observed a reduction in both molecular weights $\bar{M}_{w}$ and $\bar{M}_{n}$ coupled with a slight increase in the MWD values. These results show the dominance of chain scission mechanism with the absorbed dose due to degradation.

\section{Table 2}

Polymer degradation generally involves 2 processes: chain scission and/or crosslinking which change molecular weights and molecular weight distribution. In the absence of cross-linking, main chain scissions result in a decrease of both $\bar{M}_{n}$ and $\bar{M}_{w}$. In this respect, Figure 5 shows the changes in the average number of chain scission $\left(n_{t}\right)$ per unit mass at 1 and $10 \mathrm{kGy}$ for the neat PHBV, neat PLA, PHBV/PLA blend and PHBV/PLA/C30B nanocomposite samples. From Figure 5, it is observed the linearity of the plots during eBeam irradiation for all the samples with a slight increase in the value of $n_{t}$ at the absorbed dose of $1 \mathrm{kGy}$, being much higher at $10 \mathrm{kGy}$. The linearity of the plots implies that random chain scission is occurring in the irradiated samples [18]. In the absence of cross-linking confirmed by the solubility test, the decrease of both $\bar{M}_{n}$ and $\bar{M}_{w}$ with the MWD tending to 2 indicates random scission as the dominant degradation mechanism. Further, it is also interesting to notice that at $10 \mathrm{kGy}$, the average number of chain scission is much lower for neat PLA than neat PHBV and PHBV/PLA blend although these materials are all sensitive to ionizing radiations. Whereas, the lowest $n_{t}$ value is observed for the nanocomposite sample. This result suggests that the incorporation of C30B reduces the degradation process of PHBV/PLA blend under eBeam irradiation. This is consistent with the results obtained by FT-IR spectroscopic analysis and in line with the literature data [19].

\subsection{Thermogravimetric analysis (TGA)}

Table 3 summarizes the values of degradation temperatures at 5, 10 and 50\% weight loss and the maximum degradation rate for neat PHBV, neat PLA, PHBV/PLA blend and 
PHBV/PLA/C30B nanocomposite before and after absorbed doses of 1 and $10 \mathrm{kGy}$. Furthermore, the $\%$ char yield at $600^{\circ} \mathrm{C}$ is also reported.

\section{Table 3}

According to the data reported in Table 3, neat PLA exhibits the highest thermal stability $\left(\mathrm{T}_{5 \%}=332^{\circ} \mathrm{C}\right)$ compared to the rest of the samples before irradiation, while the lowest one is observed for the neat PHBV $\left(\mathrm{T}_{5 \%}=267^{\circ} \mathrm{C}\right)$. Furthermore, the thermal stability of PHBV/PLA blends whose $T_{5 \%}=276^{\circ} \mathrm{C}$ is increased by $10^{\circ} \mathrm{C}$ after adding C30B.The other degradation temperatures, i.e. $\mathrm{T}_{10 \%}, \mathrm{~T}_{50 \%}$ and $\mathrm{T}_{\max }$ shift to higher values passing from 282, 312 and 287/362 ${ }^{\circ} \mathrm{C}$ for PHBV/PLA blend to 291,320 and $299 / 363^{\circ} \mathrm{C}$ for the nanocomposite sample, respectively.These resultsare expected regarding the presence of layered silicates in the PHBV/PLA blend, which reduce the diffusion of the volatile degradation products of the nanocomposite sample and also to better interactions between the organomodified clay and the polymeric matrix [16]. After eBeam irradiation, the thermal stability of neat PHBV, neat PLA and PHBV/PLA blend is affected to some extent, since a decrease in the degradation temperatures is observed, being however, more pronounced at absorbed dose of $10 \mathrm{kGy}$. This is due probably to chain scissions resulting from the degradation of the irradiated materials.

On the contrary, the results given in Table 2 show that PHBV/PLA/C30B nanocomposite is more thermally stable than the virgin blend even at absorbed dose of $10 \mathrm{kGy}$. The degradation temperatures remain almost unchanged. This clearly demonstrates that C30B can absorb volatile products emitted during the thermal degradation and simultaneously may act as an insulating barrier towards eBeam radiation.

\subsection{Differential Scanning Calorimetry (DSC)}

The results from Table 4 indicate the evolution of thermal characteristics for neat PHBV, neat PLA, PHBV/PLA blend and PHBV/PLA/C30B nanocomposite before and at target doses of 1 and $10 \mathrm{kGy}$, i.e. $\mathrm{T}_{\mathrm{c}}, \Delta \mathrm{H}_{\mathrm{c}}$ recorded in the cooling scan and $\mathrm{T}_{\mathrm{cc}}, \Delta \mathrm{H}_{\mathrm{cc}}, \mathrm{T}_{\mathrm{m}}$ and $\Delta \mathrm{H}_{\mathrm{m}}$ determined from the second heating scan. Some information about changes in the morphology of the samples exposed to eBeam radiations can be deduced from DSC data.

\section{Table 4}

Before exposure to eBeam irradiation, the DSC thermograms of neat PHBV and neat PLA display only one single endothermic melting peak (at 171 and $150^{\circ} \mathrm{C}$, respectively), which is characterized by a melting enthalpy of 93 and $24 \mathrm{~J} / \mathrm{g}$, respectively. As expected, the DSC thermogram for PHBV/PLA blend reveals two melting peaks located at 170 and $150^{\circ} \mathrm{C}$, corresponding to those of neat polymers. In the case of PHBV/PLA/C30B nanocomposite, all 
the values of the thermal characteristics, i.e. $T_{c}, T_{c c}, \Delta H_{c}, \Delta H_{c c}, T_{m}$ and $\Delta H_{m}$, are slightly reduced, compared to those determined for PHBV/PLA blend. This can be explained by a modification in the macromolecular arrangements of PHBV and PLA chains influenced by the presence of C30B, as previously shown [10,17].

At target doses of 1 and $10 \mathrm{kGy}$, the melting peak of neat PHBV shifts to lower temperatures, i.e. 170 and $166^{\circ} \mathrm{C}$, respectively, while the melting enthalpy significantly increases with target doses. The PLA behavior is quite different as we observe a duplication of the melting peak. However, both melting temperatures corresponding to the two maxima of the duplicated peak decrease and the resulting melting enthalpy increases, with the increase in the target dose. The specific evolution relative to the PLA morphology is explained by the molecular reorganization of PLA chains and the occurrence of different crystal populations after irradiation [17].

The same trend is pointed out for PHBV/PLA blend and PHBV/PLA/C30B nanocomposite after eBeam irradiation, which induces the decrease of the melting temperatures of PHBV and PLA, the duplication of PLA melting peak and the increase of the melting enthalpy in any case. It can be also noted that the peak corresponding to the crystallization temperature shifts to lower temperatures and that the crystallization enthalpy slightly increases as a function of absorbed dose. Besides this, the crystallization temperature of PHBV and PLA tends to slightly decrease while the crystallization enthalpy decreases with increasing the absorbed dose. All these results mean that the eBeam irradiation promotes the appearance of some defects in the PHBV and PLA matrices implying significant changes in their morphologies. The increase of the melting enthalpy regarding the target dose is related to a well-known phenomenon as chemi-crystallization [20]. This term defines the increase of the crystallinity during the irradiation process as a result of liberation of macromolecular fragments. This is due to the chain scission mechanism that leads to the formation of shorter polymer chains, as previously shown by the increase of the average number of chain scissions when the target dose increases (Figure 5). The resulting polymer chains then have higher mobility and they can reorganize themselves which leads to an increase of the crystallinity, as a function of the target dose. This explanation is further supported by the evolution of the crystallization characteristics $\left(\mathrm{T}_{\mathrm{c}}\right.$ and $\Delta \mathrm{H}_{\mathrm{c}}$ for neat PHBV; $\mathrm{T}_{\mathrm{cc}}$ and $\Delta \mathrm{H}_{\mathrm{cc}}$ for neat PLA) after eBeam irradiation since the production of shorter polymer chains is a necessary precondition for the increase of the mobility of macromolecules which reinforces their potential for reorganization and crystallization at a lower temperature [21-23]. 


\subsection{Water vapor transmission rate (WVTR)}

The barrier properties of polymer films are essential for packaging application [24]. A modification in the crystalline state of polymer induced by filler incorporation may affect the gas barrier properties since the crystalline phase is usually considered to be impermeable to the molecules diffusion. It is established that crystals in a polymer matrix reduce the water transmission due to their small cross-sectional [25] and low permeability restricting chain mobility and subsequently lower water permeability. The water vapor permeability (WVP) of neat PHBV, neat PLA, PHBV/PLA blend and PHBV/PLA/C30B nanocomposite was investigated using the "Cups methods" at $23^{\circ} \mathrm{C}$ and $50 \% \mathrm{RH}$. The resulting WVP data are presented in Table 5. Before exposure of the samples to eBeam irradiation, PHBV exhibits the lowest value of WVP coefficient $\left(0.17\right.$ g.m.s $\left.{ }^{-1} \cdot \mathrm{Pa}^{-1} \cdot 10^{-11}\right)$ than PLA $\left(1.22\right.$ g.m.s ${ }^{-1} \cdot \mathrm{Pa}^{-1} \cdot 10^{-}$ ${ }^{11}$ ) due to the highly crystalline phase of PHBV, which has a positive effect on water vapor barrier properties. Accordingly, the incorporation of PHBV to PHBV/PLA blend is more effective at improving the barrier properties of the blend materials.

\section{Table 5}

As reported in the literature [10], the inclusion of impermeable crystallites in PHBV/PLA blend decreases the amount of amorphous phase in PLA through which the gas molecules can permeate. On the other hand, the incorporation of C30B into PHBV/PLA blend promotes the crystallinity of the nanocomposite sample, thus exerting significant effects on the water vapor permeability coefficient as shown in the data reported in Table 5. Indeed, the value of WVP coefficient of PHBV/PLA, which is initially $0.45 \mathrm{~g} \cdot \mathrm{m} . \mathrm{s}^{-1} \cdot \mathrm{Pa}^{-1} \cdot 10^{-11}$ decreases to $0.37 \mathrm{~g} \cdot \mathrm{m} . \mathrm{s}^{-1} \cdot \mathrm{Pa}^{-}$ ${ }^{1} .10^{-11}$ after adding C30B. This is interpreted as a result of C30B, which enhances the barrier effect toward the water vapor through a better dispersion of silicate sheets as well as a strong interfacial adhesion. This leads to the increase of the tortuous diffusion pathways induced by the presence of impermeable domains of $\mathrm{C} 30 \mathrm{~B}$, which act as obstacles to the transfer of molecules. At absorbed dose of 10 kGy, Table 5 shows a large decrease in the values of WVP coefficient for all the irradiated samples due probably to the chemicrystallization phenomenon. Indeed, for semi-crystalline polymers, the chain scissions resulting from the radiochemical degradation are responsible for molar mass decay, but also for crystallinity increase. This is due to the fact that the chain fragments induced by chain scissions in the amorphous region can integrate the crystalline phase by a lamellar thickening process [26]. The increase in crystallinity observed in the whole irradiated samples, especially at absorbed 
dose of $10 \mathrm{kGy}$ is the most effective parameter responsible for improving the barrier properties of the polymers.

\subsection{Nanoindentation measurements}

Knowledge of mechanical properties at the nano-level can be important for certain materials selection and design criteria and applications [27]. Nanoindentation tests have been carried out in attempt to analyze the effect of eBeam irradiation on modulus (E) and hardness $(\mathrm{H})$ of neat PHBV, neat PLA, PHBV/PLA blend and PHBV/PLA/C30B nanocomposite at absorbed doses of 1 and $10 \mathrm{kGy}$. In this respect, the nanoindentation data are reported in Table 6 . The values are averaged for indentation depths of 1200 - $1500 \mathrm{~nm}$ from a minimum of 64 indents. A Poisson's ratio of 0.35 was used in all modulus calculations.

\section{Table 6}

From the data given in Table 6, it is observed a decrease in the E values of neat PHBV, neat PLA and PHBV/PLA blend with increasing the absorbed dose. Furthermore, At $10 \mathrm{kGy}$, the decrease in the nanoindentation modulus is much pronounced for the neat polymers, in particular PHBV. On the contrary, the effect of eBeam irradiation on hardness seems to be negligible; the values remain almost unchanged within the experimental errors even at absorbed dose of $10 \mathrm{kGy}$.

As expected, the incorporation of C30B to PHBV/PLA blend induces a slight increase in the E value by almost 4\% compared to that of the virgin blend, which can be correlated with the dispersion of nanoclay and its d-spacing. Indeed, the higher the $\mathrm{d}$-spacing values, better is the dispersion of nanoclay in the polymer matrix and higher is the modulus [28]. After exposure to eBeam irradiation, the nanocomposite sample exhibits higher modulus with $9 \%$ increase at absorbed dose of $10 \mathrm{kGy}$ compared to the non irradiated one. Indeed, the $\mathrm{E}$ value of the PHBV/PLA/C30B nanocomposite is $5.5 \pm 0.3 \mathrm{GPa}$ before irradiation and the value increases to $6 \pm 0.3 \mathrm{GPa}$ at target dose of $10 \mathrm{kGy}$. Although, the literature data [29] reported on the sensitivity of nanoindentation toward chain scission, the increase in modulus for the irradiated nanocomposite sample may result from both the positive effect induced by the clay dispersion and the crystallinity increase due to chemi-crystallization [20].

\subsection{Scanning electron microscopy (SEM)}

SEM was used to characterize the changes induced by eBeam irradiation on the morphology of PHBV/PLA blend with and without C30B. In this respect, Figure 6 shows the SEM micrographs of the fracture surface of neat PHBV, neat PLA, PHBV/PLA blend and 
PHBV/PLA/C30B before irradiation and at target dose of $10 \mathrm{kGy}$ recorded at magnification of 2000X. The fracture surface of neat PHBV before irradiation is shown in Figure 6(a). An irregular fracture surface is observed due to the crystal structure of PHBV [11]. However, these irregularities become more accentuated at absorbed dose of $10 \mathrm{kGy}$ as illustrated in Figure 6(b), which may be due to an increase in crystallinity. Indeed, previous results of our group $[\mathbf{1 4 , 3 0 ]}$ reported that the crystallinity increases with the radiation dose due to chemicrystallization phenomenon. The SEM micrograph of the fracture surface of neat PLA exhibits a regular and smooth surface. After $10 \mathrm{kGy}$, no remarkable change is observed except the roughness of the fracture surface compared to the non irradiated one (micrographs not shown here).

Figure 6(c) shows the SEM micrograph of the fracture surface of PHBV/PLA blend before irradiation. PHBV/PLA blends exhibit separated phase morphology and there is a poor adhesion at the interfaces, as described in a previous article [11]. The separated phase morphology is discernible, signifying immiscibility between the two biopolymers. At absorbed dose of $10 \mathrm{kGy}$, similar morphology is observed indicating no damage on the fracture surface of the irradiated sample (micrograph not shown here). The addition of C30B results in improved interfacial adhesion between PHBV and PLA as shown in Figure 6(d). At absorbed dose of $10 \mathrm{kGy}$, the fracture surface of the irradiated sample seems also to be stable (micrograph not shown here).

\subsection{Transmission electron microscopy (TEM)}

One of the primary objectives of the study was to examine the state of dispersion of C30B nanoparticles resulting from the melt compounding process. Both the distribution and dispersion of C30B aggregates inside the PHBV/PLA blend are favored during melt mixing. In general, if the clay is perfectly dispersed in its form as individual silicate layers, the nanocomposite is referred as exfoliated. However, the common structure obtained after melt compounding shows a stack of several layers. The other objective was to investigate the effect of eBeam irradiation on the nanocomposite structure. In this respect, the structure of PHBV/PLA/C30B before eBeam irradiation and at absorbed doses of 1 and $10 \mathrm{kGy}$ is shown in TEM micrographs of Figure 7(a), (b) and (c), respectively. It is observed in Figure 7(a) that С30B is predominantly in the form of thin stacks made of a few layers. However, individual clay layers are also noticed. Accordingly, the TEM observations suggest that PHBV/PLA/C30B nanocomposite exhibits only partially exfoliated/intercalated structure. On 
the other hand, the TEM micrographs presented in Figure 7(b) and (c) corresponding to the irradiated nanocomposite sample at 1 and $10 \mathrm{kGy}$, respectively reveal no noticeable change in the structure of the nanocomposite, which is similar to that of the non irradiated one. This result which is in agreement with the SEM observations suggests that up to the target dose of $10 \mathrm{kGy}$, the effect of eBeam irradiation on the structure of PHBV/PLA/C30B nanocomposite is negligible.

\subsection{Ecotoxicity test}

Ecotoxicity tests are tools used within environmental hazard assessment frameworks to answer questions about the intrinsic dangers of chemical substances which may be released into the environment. When such hazard assessments are compared with exposure assessments, the potential risk of adverse effects can be characterized [31]. Table 7 reports the ecotoxicity data for neat PHBV, neat PLA, PHBV/PLA blend and PHBV/PLA/C30B nanocomposite before eBeam irradiation and at absorbed doses of 1 and $10 \mathrm{kGy}$.

\section{Table 7}

From Table 7, the data show clearly that the irradiated samples irrespective of whether it is 1 kGy or 10 kGy are not releasing toxic byproducts and therefore based on the food simulants that were employed are toxicologically inert.

\section{Conclusion}

The results reported in this paper show that eBeam irradiation causes some changes in the chemical structure of neat PHBV, neat PLA and PHBV/PLA blend at absorbed dose of 10 kGy through the transformations of ester groups to mainly hydroxyl groups. Furthermore, random chain scission is the predominant degradation mechanism. These structural modifications induced a decrease in the functional properties of the materials. Although, the incorporation of C30B to PHBV/PLA blend has no effect on the nature of the degradation mechanism; however, the good dispersion of the C30B nanoparticles in the polymer matrix observed by TEM lowers the evolution of the average number of chain scissions compared to the virgin blend. Consequently, stability of thermal, mechanical and barrier properties is obtained at absorbed dose of $10 \mathrm{kGy}$. Though there were drastic changes in the chemical structure of the blends, there was no resulting toxicity as measured using the luminescent bacteria-based bioassay (Microtox).

\section{Acknowledgements}


The authors would like to thank the International Atomic Energy Agency (IAEA)- Vienna (Austria) through the Research Contract $n^{\circ} 17692 / \mathrm{R} 3$ and they are also grateful to EGIDE through the TASSILI program 12 MDU 871 for its financial support in this collaborative project. The authors are pleased to express their grateful acknowledgements to Dr. Alain Bourmaud, Antoine Kervoelen, Anthony Magueresse and Françoise Peresse for their help in the experimental work. Thanks to A.V. Buys from the University of Pretoria (South Africa) for performing TEM analysis. Funds from the Texas A\&M AgriLife Research project H8708 were used as part of this project in the eBeam irradiation studies.

\section{References}

[1] B. Panea, G. Ripoll, J. González, Á. Fernández-Cuello, P. Albertí, J. Food Eng. 124 (2014) 104.

[2] M. Salvatore, A. Marra, D. Duraccio, S. Shayanfar, S.D. Pillai, S. Cimmino, C. Silvestre, J. Appl. Polym. Sci. 133 (2016) 42219.

[3] D.Z. Bucci, L.B.B. Tavares, I. Sell, Polym. Test. 24 (2005) 564.

[4] Si.Y. Lee, T. Kamarul, Inter. J. Biological Macromol. 64 (2014) 115.

[5] M.F. Romanelli, M.C.F. Moraes, A.L.C.H. Villavicensio, S.I. Borrely, Rad. Phys. Chem. 71 (2004) 409.

[6] M. Haji-Saeid, M.H.O. Sampa, A.G. Chmielewski, Rad. Phys. Chem.76 (2007) 1535.

[7] L. Woo, C.L. Sandford, Rad. Phys. Chem. 63 (2002) 845.

[8] M.L. Cairns, G.R. Dickson, J.F. Orr, D. Farrar, K. Hawkins, F.J. Buchanan, Polym. Degrad. Stab. 96 (2011) 76.

[9] S.C.J. Loo, C.P. Ooi, Y.C.F. Boey, Polym. Degrad. Stab. 83 (2004) 259.

[10] I. Zembouai, M. Kaci, S. Bruzaud, L. Dumazert, A. Bourmaud, M. Mahlous, J.-M. Lopez-Cuesta, Y. Grohens, Polym. Test. 49 (2016) 29.

[11] I. Zembouai, M. Kaci, S. Bruzaud, A. Benhamida, Y.M. Corre, Y. Grohens, Polym.Test. 32 (2013) 842.

[12] I. Zembouai, S. Bruzaud, M. Kaci, A. Benhamida, Y.M. Corre, Y. Grohens, A. Taguet, J.M. Lopez-Cuesta, J. Polym. Env. 22 (2014) 449.

[13] I. Zembouai, S. Bruzaud, M. Kaci, A. Benhamida, Y.M. Corre, Y. Grohens, J.M. Lopez-Cuesta, Polym. Eng. Sci. 54 (2014) 2239.

[14] I. Zembouai, S. Bruzaud, M. Kaci, A. Benhamida, Y.M. Corre, Y. Grohens, J. Polym. Env. 22 (2014) 131. 
[15] M. Deroiné, A. Le Duigou, Y.M. Corre, P.Y. Le Gac, P. Davies, G. César, S. Bruzaud, Polym. Degrad. Stab. 108 (2014) 319.

[16] S. Bruzaud, A. Bourmaud, Polym. Test. 26 (2007) 652.

[17] L. Zaidi, S. Bruzaud, M. Kaci, A. Bourmaud, N. Gautier, Y. Grohens, Polym. Degrad. Stab. 98 (2013) 348.

[18] Jean F. Rabek. Photodegradation of polymers: Physical characteristics and applications. Edited by Springer, $1^{\text {st }}$ Edition, Berlin Heidelberg 1996, p 125.

[19] H. Zhao, Z. Cui, X. Sun, L.-S.Turng, X. Peng, Ind. Eng. Chem. Res. 52 (2013) 2569.

[20] B. Fayolle, J. Verdu, Eur. Polym. J. 47 (2011) 2145.

[21] L. Zaidi, S. Bruzaud, A. Bourmaud, P. Médéric, M. Kaci, Y. Grohens, J. Appl. Polym.Sci. 116 (2010) 1357.

[22] M. Liu, Y. Yin, Z. Fan, X. Zheng, S. Shen, P. Deng, Nucl. Instr. Meth. Phys. Res. B 274 (2012) 139.

[23] R.E. Lyon, R.N.Walters, J.Anal. Appl. Pyrol. 71 (2004) 27.

[24] K. Issaadi, A. Habi, Y. Grohens, I. Pillin, Appl. Clay Sci. 107 (2015) 62.

[25] B.S. Bouakaz, I. Pillin, A. Habi, Y. Grohens, Appl. Clay Sci.116-117 (2015) 69.

[26] O. Okamba-Diogo, E. Richaud, J. Verdu, F. Fernagut, J. Guilment, B. Fayolle, Polymer 82 (2016) 49.

[27] C. Remili, M. Kaci, A. Benhamida, S. Bruzaud, Y. Grohens, Polym. Degrad. Stab. 96 (2011) 1489.

[28] G. Perego, G. Domenico, C. Bastioli, J. Appl. Polym. Sci. 59 (1996) 37.

[29] G. Filippone, S.C. Carroccio, G. Curcuruto, E. Passaglia, C. Gambarotti, N.T. Dintcheva, Polymer 73 (2015) 102.

[30] N. Touati, M. Kaci, H. Ahouari, S. Bruzaud, Y. Grohens, Macromol. Mater. Eng. 292 (2007) 1271.

[31] M. Crane, R.D. Handy, J. Garrod, R. Owen, Ecotoxicology 17 (2008) 421. 
Table 1. Code and composition of samples used

\begin{tabular}{lccc}
\hline Samples & PHBV (wt \%) & PLA (wt \%) & C30B (wt \%) \\
\hline PHBV & 100 & - & - \\
PLA & - & 100 & - \\
PHBV/PLA & 50 & 50 & 3 \\
PHBV/PLA/C30B & 48.5 & 48.5 & 3 \\
\hline
\end{tabular}

Table 2. Molecular weight changes for the neat PHBV, neat PLA, PHBV/PLA and PHBV/PLA/C30B samples before and after eBeam irradiation at 1 and 10 kGy determined by SEC analysis.

\begin{tabular}{|c|c|c|c|c|}
\hline Samples & $\begin{array}{c}\text { Target dose } \\
\text { (kGy)* }\end{array}$ & $\begin{array}{c}\overline{\mathrm{M}}_{\mathrm{w}} \\
\left(\mathbf{g} \cdot \mathrm{mol}^{-1}\right)\end{array}$ & $\begin{array}{c}\overline{\mathrm{M}}_{\mathrm{n}} \\
\left(\mathrm{g} \cdot \mathrm{mol}^{-1}\right)\end{array}$ & $\overline{\mathrm{M}}_{\mathrm{w}} / \overline{\mathrm{M}}_{\mathrm{n}}$ \\
\hline \multirow[t]{3}{*}{ PLA } & 0 & 174000 & 105000 & 1.65 \\
\hline & 1 & 119000 & 71500 & 1.66 \\
\hline & 10 & 99700 & 59000 & 1.69 \\
\hline \multirow[t]{3}{*}{ PHBV } & 0 & 231000 & 153000 & 1.60 \\
\hline & 1 & 109000 & 72600 & 1.62 \\
\hline & 10 & 78600 & 47100 & 1.67 \\
\hline \multirow[t]{3}{*}{ PHBV/PLA } & 0 & 188000 & 128000 & 1.46 \\
\hline & 1 & 116000 & 78400 & 1.47 \\
\hline & 10 & 87000 & 58600 & 1.49 \\
\hline \multirow[t]{3}{*}{ PHBV/PLA/C30B } & 0 & 176000 & 123000 & 1.43 \\
\hline & 1 & 115000 & 79000 & 1.45 \\
\hline & 10 & 99000 & 68000 & 1.46 \\
\hline
\end{tabular}


Table 3. Values of degradation temperature at $\mathrm{T}_{5 \%}, \mathrm{~T}_{10 \%}, \mathrm{~T}_{50 \%}, \mathrm{~T}_{\max }$ and char yield at $600^{\circ} \mathrm{C}$ for the neat PHBV, neat PLA, PHBV/PLA and PHBV/PLA/C30B samples before and after eBeam irradiation at 1 and $10 \mathrm{kGy}$ determined by TGA.

\begin{tabular}{|c|c|c|c|c|c|c|}
\hline Samples & $\begin{array}{c}\text { Target } \\
\text { dose(kGy)* }\end{array}$ & $\begin{array}{l}\mathbf{T}_{5 \%} \\
\left({ }^{\circ} \mathrm{C}\right)\end{array}$ & $\begin{array}{l}\mathbf{T}_{10 \%} \\
\left({ }^{\circ} \mathrm{C}\right)\end{array}$ & $\begin{array}{l}\mathbf{T}_{50 \%} \\
\left({ }^{\circ} \mathrm{C}\right)\end{array}$ & $\begin{array}{l}\mathrm{T}_{\max } \\
\left({ }^{\circ} \mathrm{C}\right)\end{array}$ & $\begin{array}{c}\text { Char yield } \\
\text { at } 600^{\circ} \mathrm{C}(\%)\end{array}$ \\
\hline PHBV & $\begin{array}{c}0 \\
1 \\
10\end{array}$ & $\begin{array}{l}267 \\
267 \\
263\end{array}$ & $\begin{array}{l}273 \\
272 \\
268\end{array}$ & $\begin{array}{l}286 \\
284 \\
280\end{array}$ & $\begin{array}{l}290 \\
286 \\
284\end{array}$ & $\begin{array}{l}1.3 \\
1.2 \\
1.1\end{array}$ \\
\hline PLA & $\begin{array}{c}0 \\
1 \\
10\end{array}$ & $\begin{array}{l}332 \\
327 \\
327\end{array}$ & $\begin{array}{l}341 \\
338 \\
337\end{array}$ & $\begin{array}{l}362 \\
361 \\
361\end{array}$ & $\begin{array}{l}368 \\
367 \\
366\end{array}$ & $\begin{array}{l}0.7 \\
0.7 \\
0.7\end{array}$ \\
\hline PHBV/PLA & $\begin{array}{c}0 \\
1 \\
10\end{array}$ & $\begin{array}{l}276 \\
274 \\
269\end{array}$ & $\begin{array}{l}282 \\
278 \\
273\end{array}$ & $\begin{array}{l}312 \\
300 \\
296\end{array}$ & $\begin{array}{l}287 / 362 \\
287 / 358 \\
282 / 353\end{array}$ & $\begin{array}{l}1.5 \\
1.5 \\
1.5\end{array}$ \\
\hline PHBV/PLA/C30B & $\begin{array}{c}0 \\
1 \\
10\end{array}$ & $\begin{array}{l}286 \\
285 \\
284\end{array}$ & $\begin{array}{l}291 \\
290 \\
289\end{array}$ & $\begin{array}{l}320 \\
314 \\
313\end{array}$ & $\begin{array}{l}299 / 363 \\
299 / 363 \\
298 / 363\end{array}$ & $\begin{array}{l}2.9 \\
2.9 \\
2.9\end{array}$ \\
\hline
\end{tabular}

*measured dose: $1.04 \pm 0.01 \mathrm{kGy}$ and $9.89 \pm 0.13 \mathrm{kGy}$, respectively. 
Table 4. Thermal characteristics for neat PHBV, neat PLA and various PHBV/PLA blends before and after eBeam irradiation at 1 and 10 kGy determined by DSC.

\begin{tabular}{|c|c|c|c|c|c|c|c|}
\hline Samples & $\begin{array}{l}\text { Target } \\
\text { dose } \\
\text { (kGy)* }\end{array}$ & $\begin{array}{c}\mathrm{T}_{\mathrm{c}, \mathrm{PHBV}} \\
\left({ }^{\circ} \mathrm{C}\right)\end{array}$ & $\begin{array}{c}\Delta \mathbf{H}_{\mathrm{c}, \text { PHBV }} \\
(\mathbf{J} / \mathrm{g})\end{array}$ & $\begin{array}{c}\mathbf{T}_{\mathrm{cc}, \mathrm{PLA}} \\
\left({ }^{\circ} \mathbf{C}\right)\end{array}$ & $\begin{array}{c}\Delta \mathbf{H}_{\mathrm{cc}, \text { PLA }} \\
(\mathbf{J} / \mathbf{g})\end{array}$ & $\begin{array}{c}\mathbf{T}_{\mathbf{m}} \\
\left({ }^{\circ} \mathbf{C}\right)\end{array}$ & $\begin{array}{r}\Delta \mathbf{H}_{\mathrm{m}} \\
(\mathrm{J} / \mathrm{g})\end{array}$ \\
\hline \multirow[t]{3}{*}{ PHBV } & 0 & 118 & 92 & - & - & 171 & 93 \\
\hline & 1 & 118 & 92 & - & - & 170 & 94 \\
\hline & 10 & 117 & 107 & - & - & 166 & 108 \\
\hline \multirow[t]{3}{*}{ PLA } & 0 & - & - & 112 & 25 & 150 & 24 \\
\hline & 1 & - & - & 111 & 35 & $149-156$ & 33 \\
\hline & 10 & - & - & 110 & 40 & $148-154$ & 37 \\
\hline \multirow[t]{3}{*}{ PHBV/PLA } & 0 & 118 & 46 & 118 & 18 & $150-170$ & 64 \\
\hline & 1 & 117 & 49 & 113 & 17 & 149-155-168 & 74 \\
\hline & 10 & 115 & 50 & 111 & 21 & 148-154-167 & 77 \\
\hline \multirow[t]{3}{*}{ PHBV/PLA/C30B } & 0 & 116 & 36 & 110 & 11 & 148-167 & 62 \\
\hline & 1 & 115 & 46 & 110 & 14 & 148-155-166 & 74 \\
\hline & 10 & 115 & 49 & 109 & 17 & 148-154-166 & 75 \\
\hline
\end{tabular}

*measured dose $1.04 \pm 0.01 \mathrm{kGy}$ and $9.89 \pm 0.13 \mathrm{kGy}$, respectively 
Table 5. Values of water vapor permeability coefficient before eBeam irradiation and at absorbed doses of 1 and 10 kGy for neat PHBV, neat PLA, PHBV/ PLA blend and PHBV/PLA/C30B nanocomposite.

\begin{tabular}{lcc}
\hline Samples & $\begin{array}{c}\text { Target dose } \\
\text { (kGy)* }\end{array}$ & $\begin{array}{c}\text { WVP } \\
\text { (g.m.s }^{-\mathbf{1}} \cdot \mathbf{P a}^{-\mathbf{1}} \mathbf{. 1 0}^{-\mathbf{1 1}} \text { ) }\end{array}$ \\
\hline PHBV & 0 & 0.17 \\
& 1 & 0.16 \\
& 10 & 0.13 \\
PLA & 0 & 1.22 \\
& 1 & 1.28 \\
PHBV/PLA & 10 & 1.41 \\
& & \\
& 0 & 0.45 \\
PHBV/PLA/C30B & 1 & 0.44 \\
& 10 & 0.35 \\
& 0 & 0.37 \\
& 1 & 0.37 \\
& 10 & 0.30 \\
\hline
\end{tabular}

*measured dose $1.04 \pm 0.01 \mathrm{kGy}$ and 9.89 \pm 0.13 kGy, respectively 
Table 6. Values of modulus and hardness determined by nanoindentation before eBeam irradiation and at absorbed doses of 1 and $10 \mathrm{kGy}$ for neat PHBV, neat PLA, PHBV/PLA blend and PHBV/PLA/C30B nanocomposite.

\begin{tabular}{cccc}
\hline Samples & $\begin{array}{c}\text { Target dose } \\
(\mathbf{k G y})\end{array}$ & $\begin{array}{c}\text { Modulus } \\
\mathbf{( G P a )}\end{array}$ & $\begin{array}{c}\text { Hardness } \\
\mathbf{( G P a )}\end{array}$ \\
\hline PHBV & 0 & $6.3 \pm 0.2$ & $0.22 \pm 0.02$ \\
& 1 & $5.2 \pm 0.1$ & $0.22 \pm 0.03$ \\
& 10 & $4.9 \pm 0.2$ & $0.19 \pm 0.03$ \\
PLA & 0 & $4.3 \pm 1.1$ & $0.11 \pm 0.03$ \\
& 1 & $4.0 \pm 0.2$ & $0.10 \pm 0.05$ \\
& 10 & $3.5 \pm 0.2$ & $0.07 \pm 0.04$ \\
PHBV/PLA & & & \\
& 1 & $5.3 \pm 0.2$ & $0.23 \pm 0.03$ \\
& 10 & $5.1 \pm 0.4$ & $0.21 \pm 0.04$ \\
& & $4.8 \pm 0.2$ & $0.18 \pm 0.02$ \\
PHBV/PLA/C30B & 0 & $5.5 \pm 0.3$ & $0.21 \pm 0.04$ \\
& 1 & $5.7 \pm 0.1$ & $0.20 \pm 0.05$ \\
& 10 & $6.0 \pm 0.3$ & $0.20 \pm 0.02$ \\
& & & \\
\hline
\end{tabular}

*measured dose 1.04 $\pm 0.01 \mathrm{kGy}$ and $9.89 \pm 0.13 \mathrm{kGy}$, respectively 
Table 7. Ecotoxicity data performed on neat PHBV, neat PLA, PHBV/PLA blend and PHBV/PLA/C30B nanocomposite before e-beam irradiation and at absorbed doses of 1 and $10 \mathrm{kGy}$.

\begin{tabular}{|c|c|c|c|c|}
\hline Samples & $\begin{array}{c}\text { Target } \\
\text { Dose } \\
\text { (kGy)* }\end{array}$ & $\begin{array}{c}\text { Toxicity in } \\
\text { Distilled Water }{ }^{1}\end{array}$ & $\begin{array}{l}\text { Toxicity in } \\
\text { Olive Oil }\end{array}$ & $\begin{array}{c}\text { Toxicity in } \\
10 \%(v / v) \text { ethanol }^{3}\end{array}$ \\
\hline \multirow[t]{3}{*}{ PHBV } & 0 & None & None & None \\
\hline & 1 & None & None & None \\
\hline & 10 & None & None & None \\
\hline \multirow[t]{3}{*}{ PLA } & 0 & None & None & None \\
\hline & 1 & None & None & None \\
\hline & 10 & None & None & None \\
\hline \multirow[t]{3}{*}{ PHBV/PLA } & 0 & None & None & None \\
\hline & 1 & None & None & None \\
\hline & 10 & None & None & None \\
\hline \multirow[t]{3}{*}{ PHBV/PLA/C30B } & 0 & None & None & None \\
\hline & 1 & None & None & None \\
\hline & 10 & None & None & None \\
\hline
\end{tabular}

*measured dose $1.04 \pm 0.01 \mathrm{kGy}$ and $9.89 \pm 0.13$ kGy, respectively

1. Toxicity detection threshold in distilled water: $6 \%$

2. Toxicity detection threshold in oil: $58 \%$

3. Toxicity detection threshold in $10 \%$ ethanol: $75 \%$ 
Figure captions

Figure 1. FT-IR spectra of neat PLA before eBeam irradiation and after an absorbed dose of $10 \mathrm{kGy}$ : (a) $1900-1600 \mathrm{~cm}^{-1}$ and (b) $3700-3400 \mathrm{~cm}^{-1}$.

Figure 2. FT-IR spectra of neat PHBV before eBeam irradiation and after an absorbed dose of $10 \mathrm{kGy}$ : (a) $1900-1500 \mathrm{~cm}^{-1}$ and (b) $3700-3400 \mathrm{~cm}^{-1}$.

Figure 3. FT-IR spectra of PHBV/PLA blend before eBeam irradiation and after absorbed doses of 1 and $10 \mathrm{kGy:} \mathrm{(a)} 1900-1600 \mathrm{~cm}^{-1}$ and (b) $3700-3400 \mathrm{~cm}^{-1}$.

Figure 4. FT-IR spectra of PHBV/PLA/C30B nanocomposite before eBeam irradiation and after absorbed doses of 1 and $10 \mathrm{kGy:} \mathrm{(a)} 1900-1600 \mathrm{~cm}^{-1}$ and (b) $3700-3400 \mathrm{~cm}^{-1}$.

Figure 5. Evolution of the average number of chain scissions $\left(n_{t}\right)$ versus absorbed dose for neat PHBV, neat PLA, PHBV/PLA blend and PHBV/PLA/C30B nanocomposite.

Figure 6. SEM micrographs (x 2000) of fracture surface of:

Neat PHBV (a): 0 kGy and (b): 10 kGy;

PHBV/PLA blend (c): 0 kGy;

PHBV/PLA/C30B nanocomposite (d): 0 kGy.

Figure 7. TEM micrographs of the PHBV/PLA/C30B nanocomposite sample:

before eBeam irradiation: (a);

at absorbed doses of $1 \mathrm{kGy}$ : (b);

at absorbed doses of $10 \mathrm{kGy}$ : (c). 


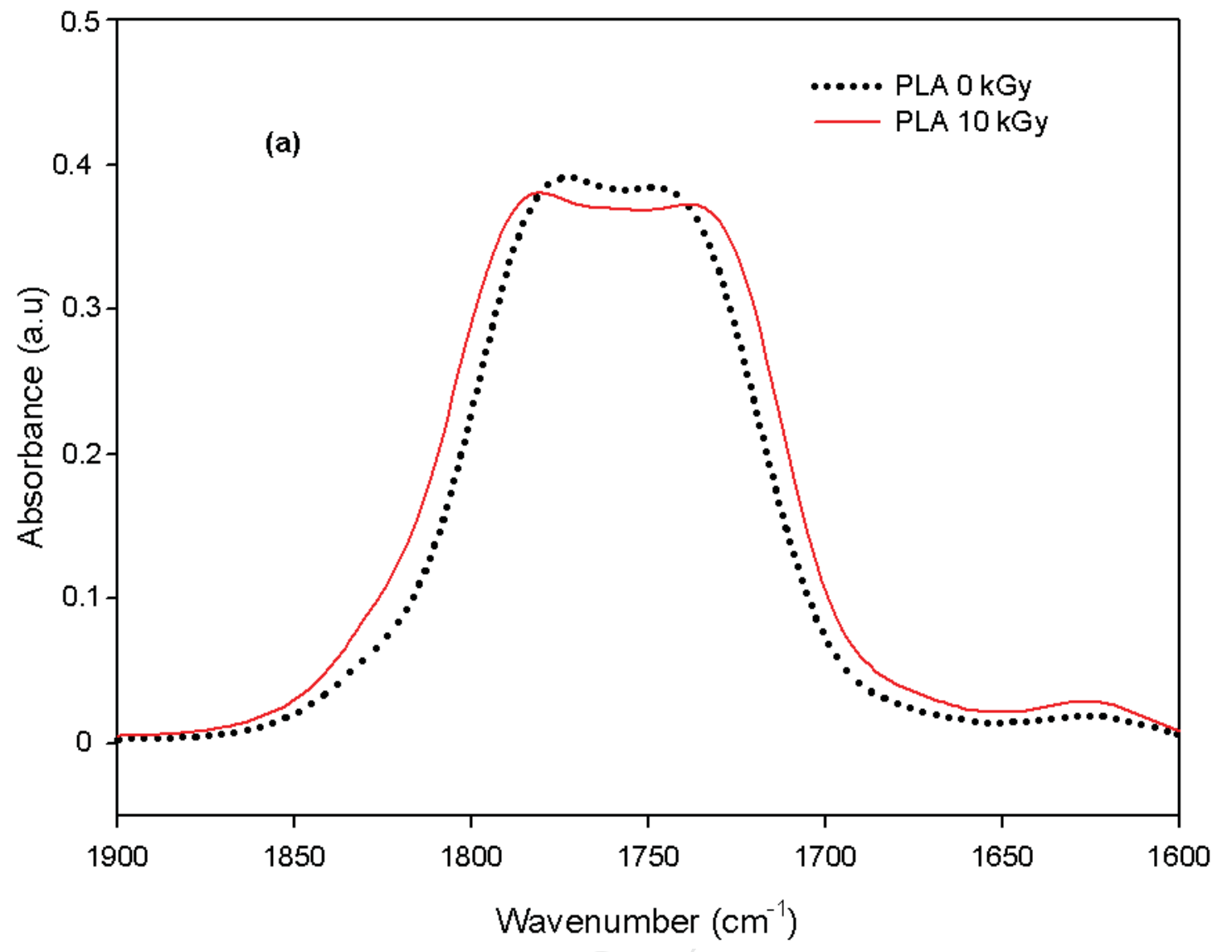




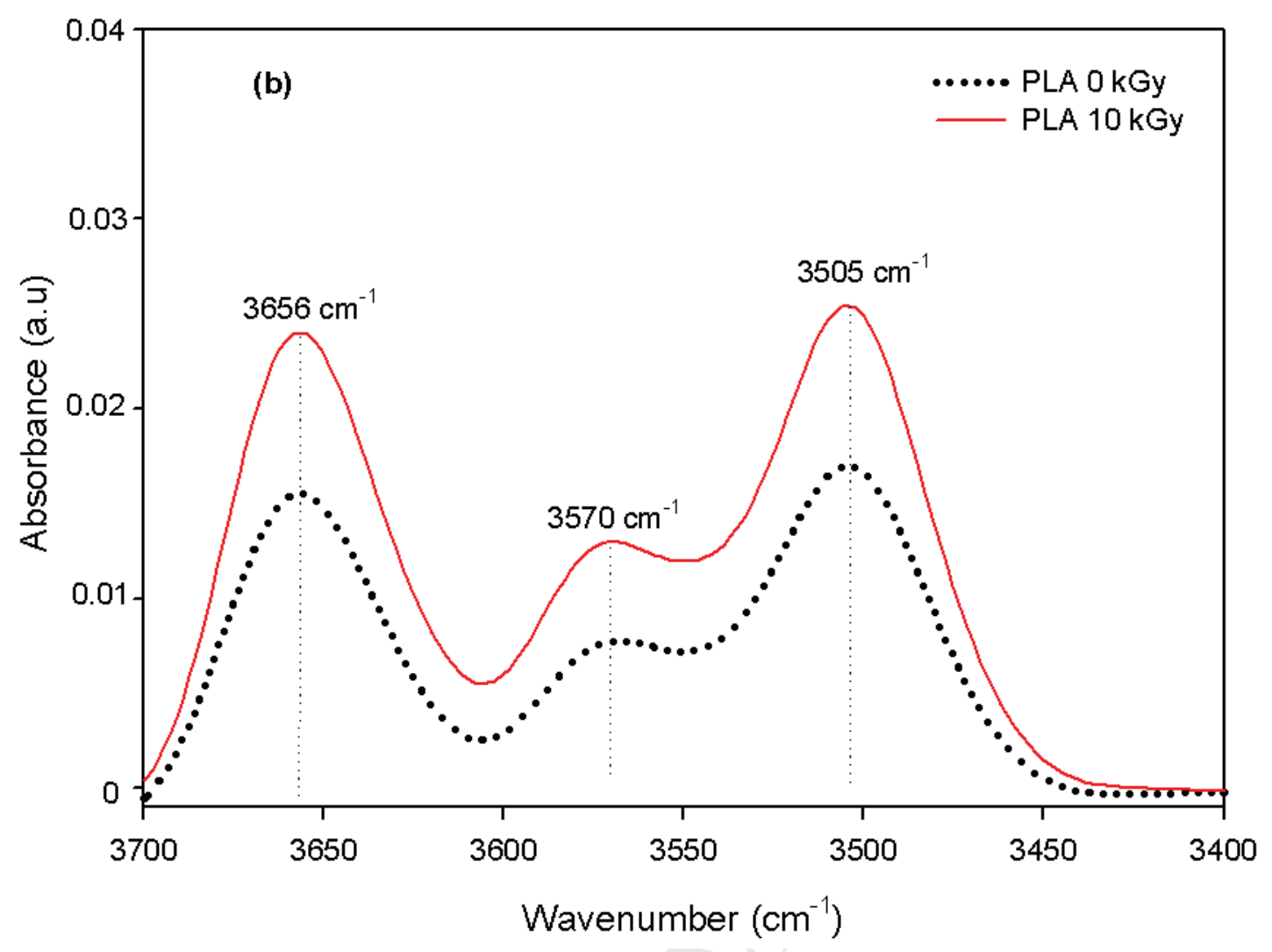




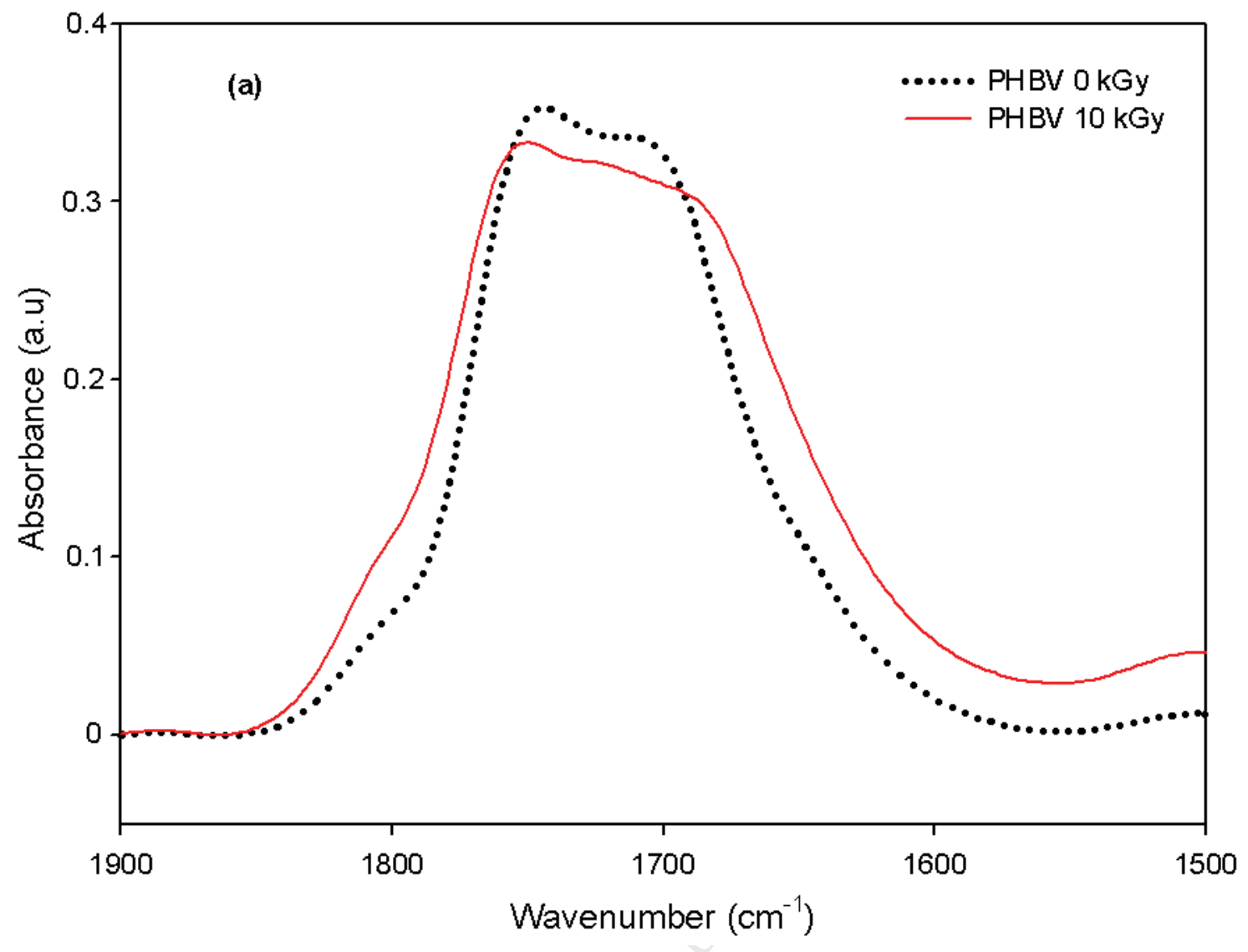




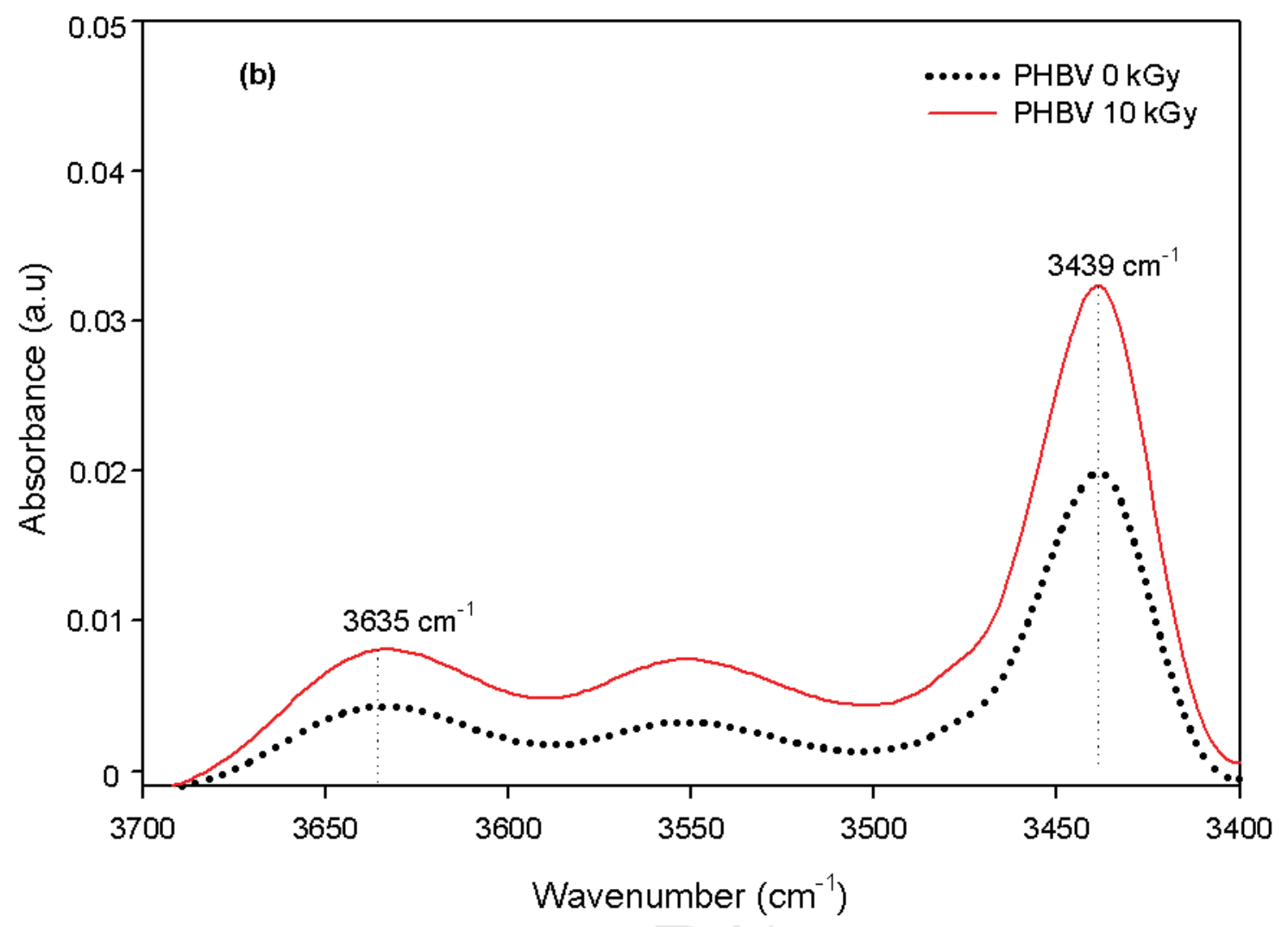




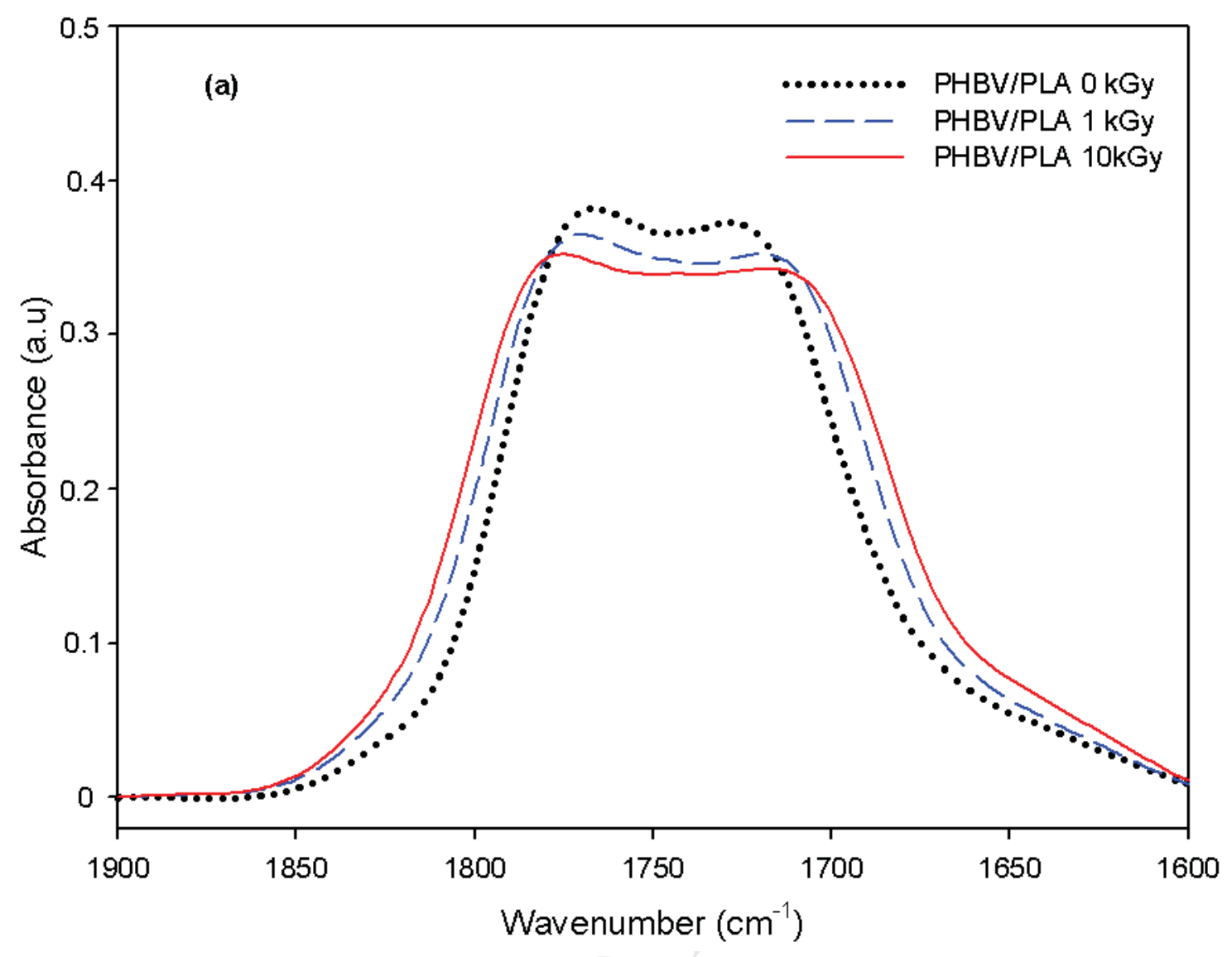




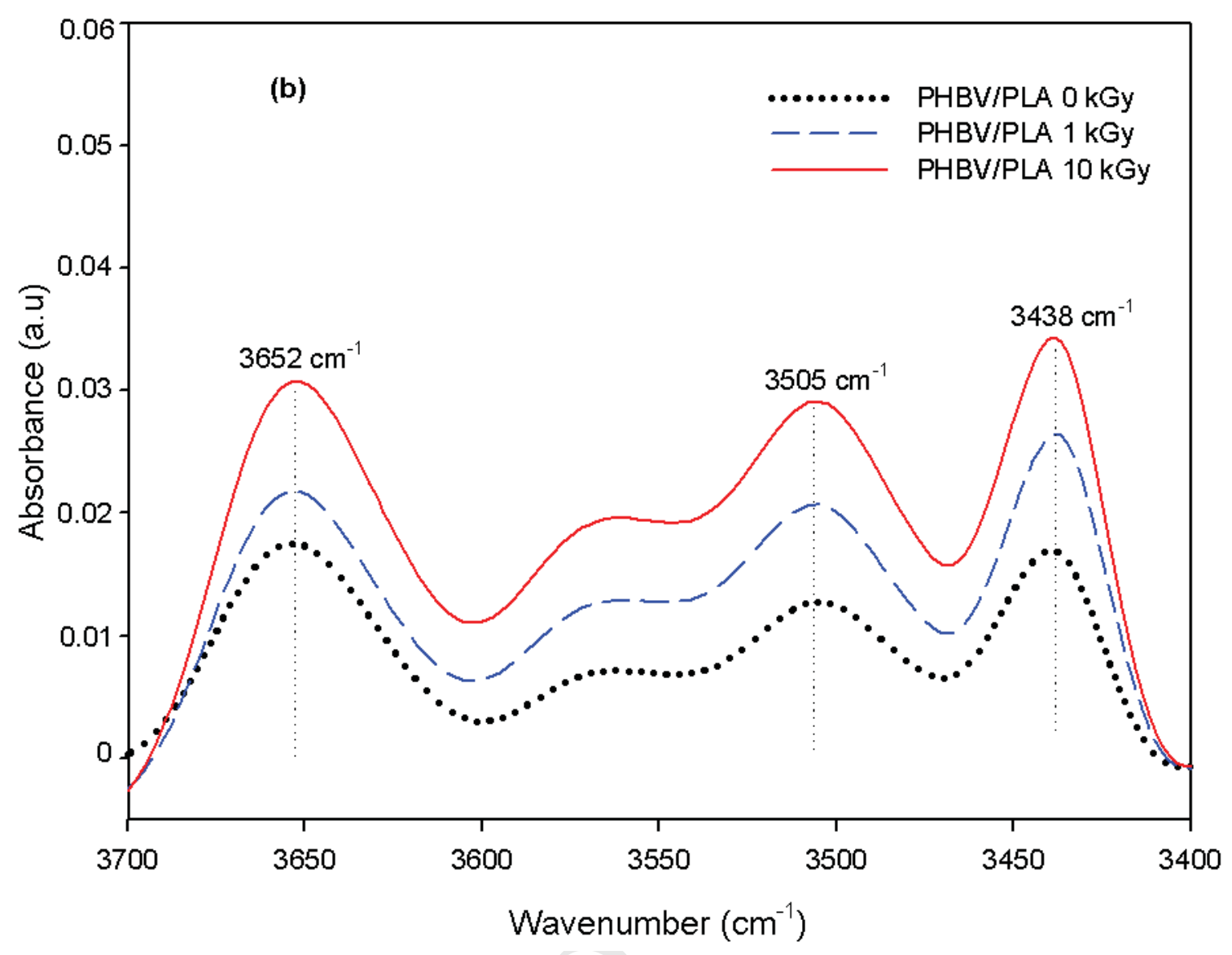




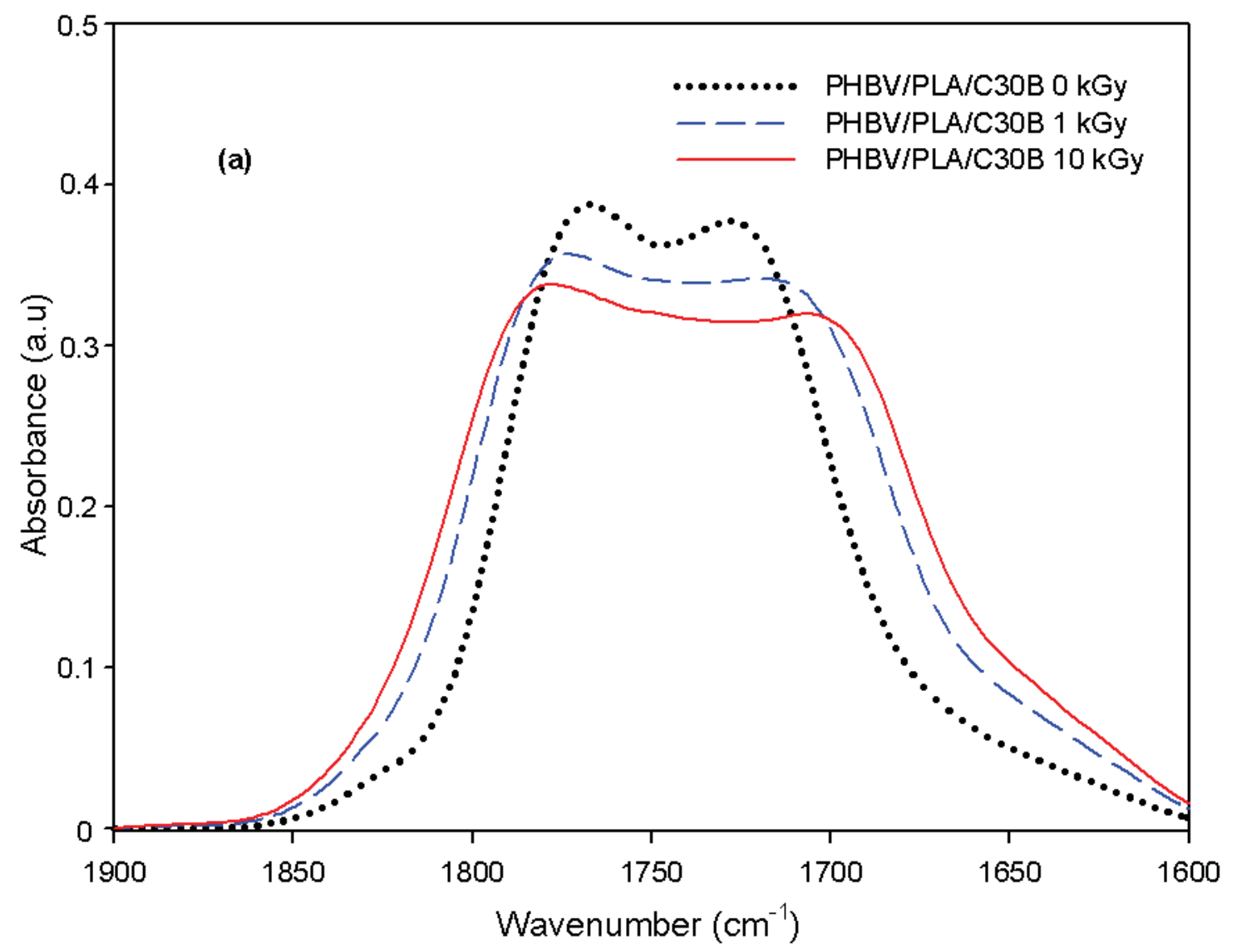




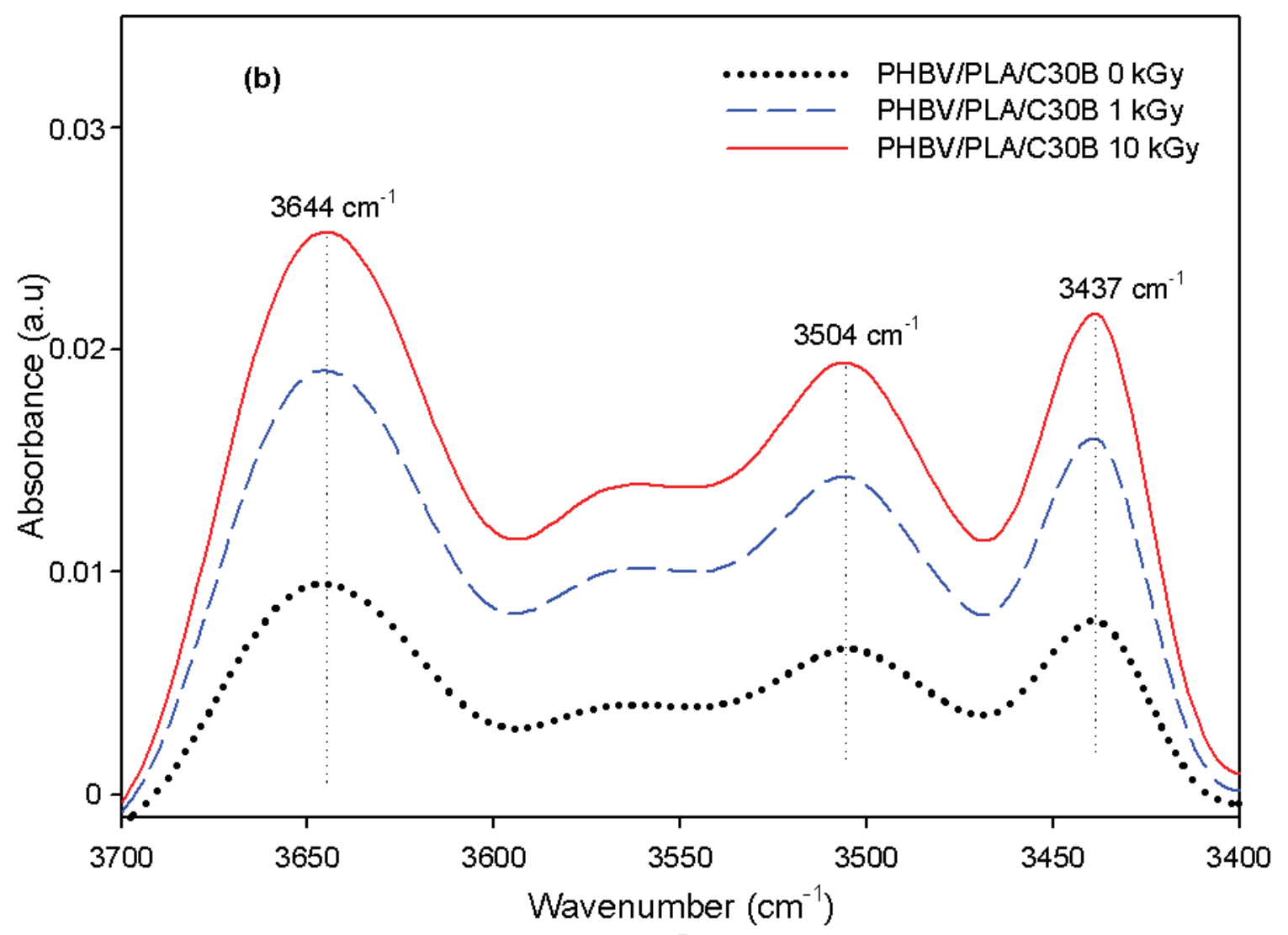




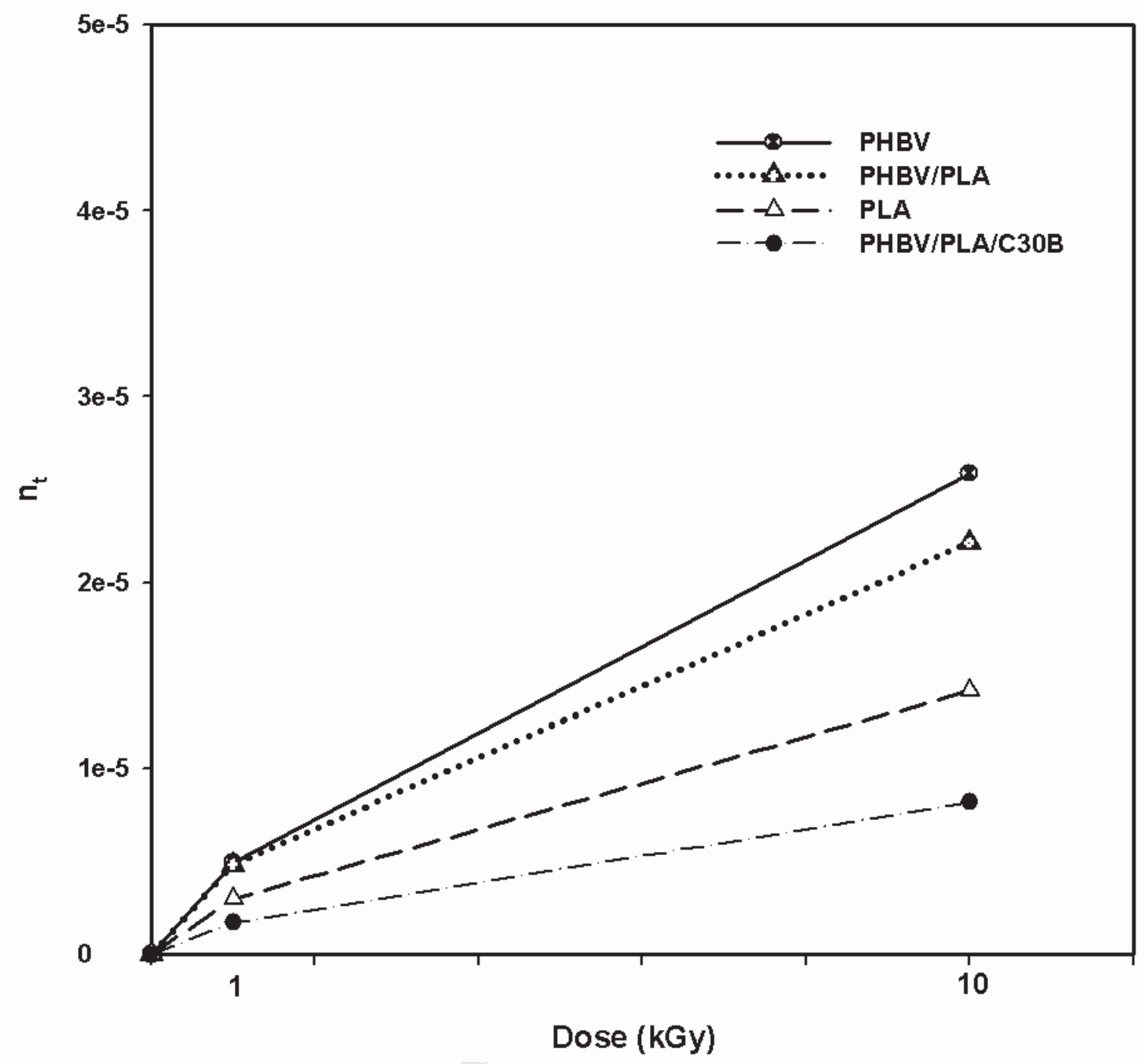




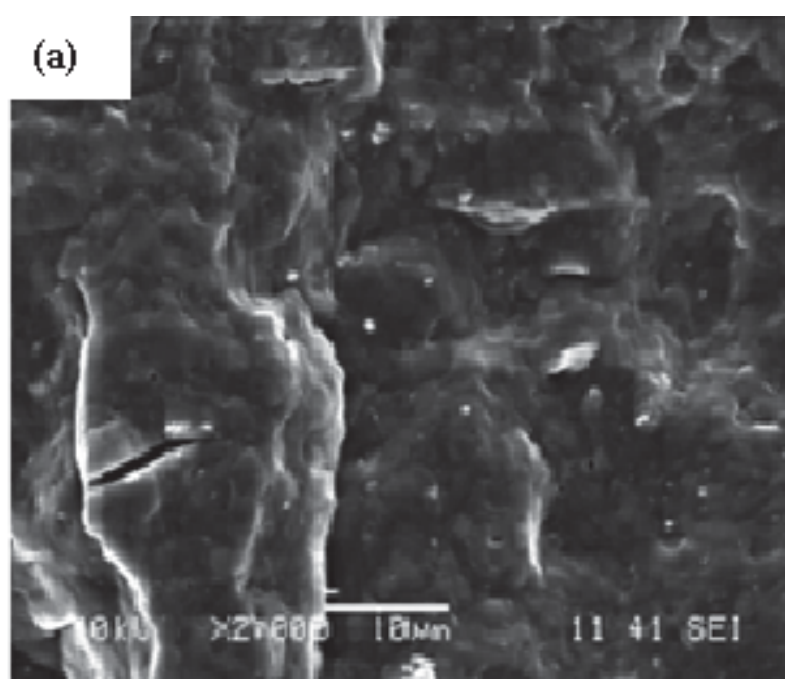




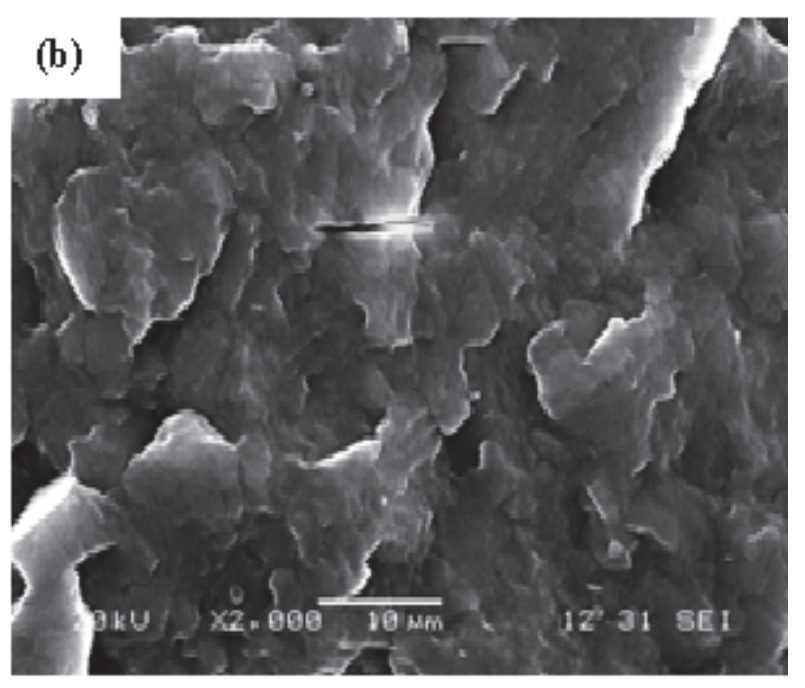




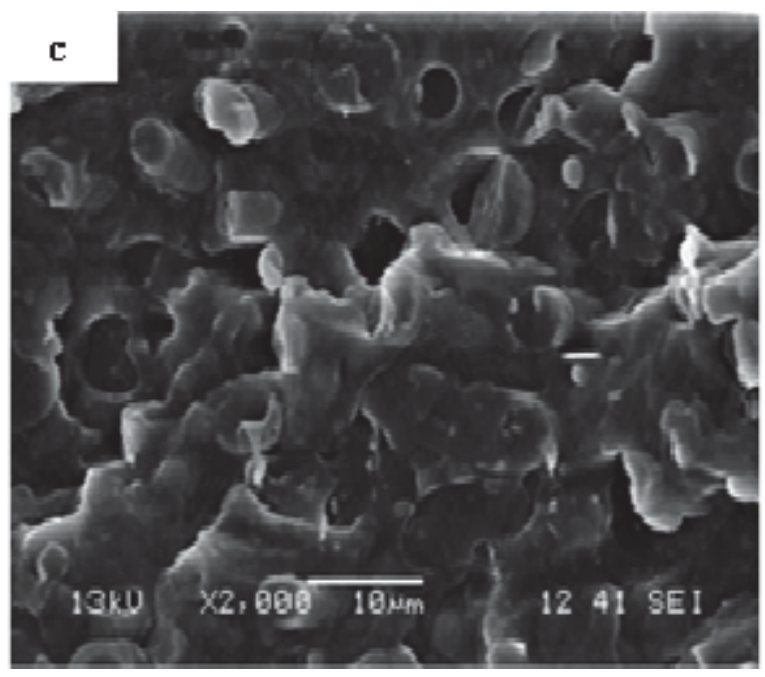




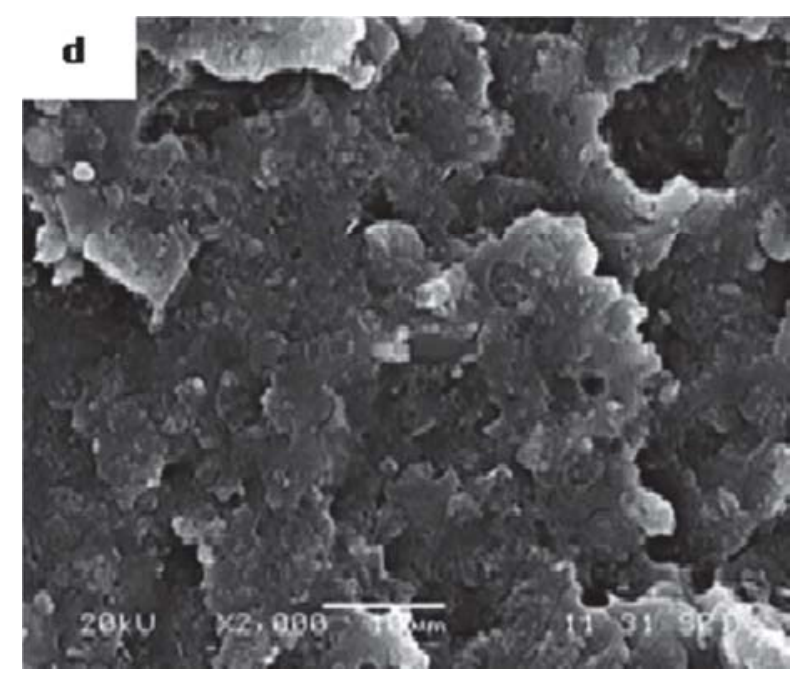


(a) 


$$
\text { (b) }
$$




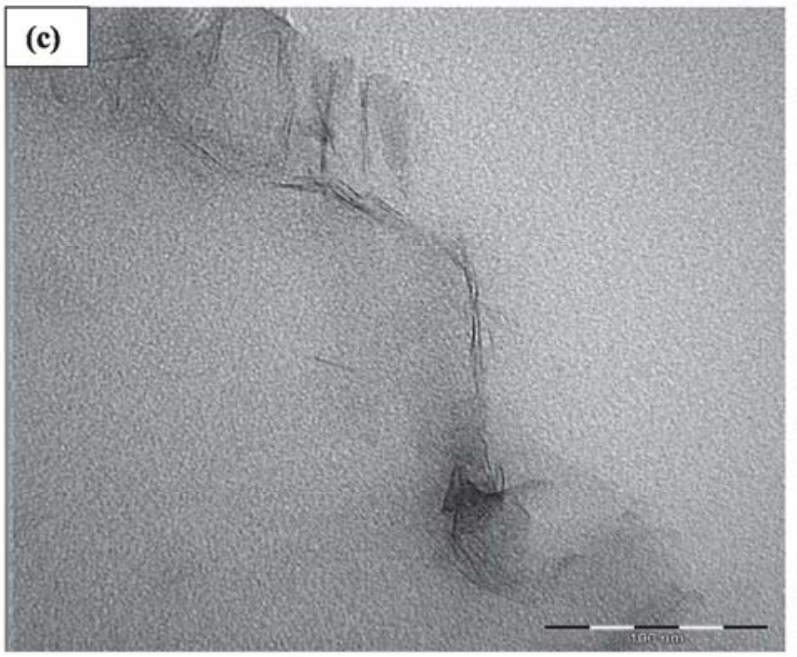

